\title{
Correspondence
}

\section{Health economics in mental health}

Sir: The two timely articles on economic evaluation in mental health (Psychiatric Bulletin, November $1997,21,684-686,687-691$ ) omitted to mention the important issue of cost of illness economic analysis.

Cost of illness analyses are important when specific disorders are considered as opposed to modes of treatment and service delivery (Shah, 1995; Smith et al, 1995). This approach attempts to measure the economic burden of disease in terms of resources used to treat the condition, the occurrence of premature mortality, and the morbidity and disability falling on sufferers and carers. These studies measure direct costs of treating the disorder and indirect costs due to loss of productivity from early mortality and disability and the financial strain on the carer. Cost of illness studies can be used to identify avoidable costs in the successful development of primary prevention or early detection and treatment resulting in secondary and tertiary prevention.

If, by using the cost of illness approach, disorder $\mathrm{A}$ is more expensive than disorder $\mathrm{B}$. treatment and research can be directed towards the more expensive disorder (Croft-Jefferys \& Wilkinson, 1989). If treatment and research resources directed at the economically more significant disorders can result in primary prevention or early detection and treatment with secondary and tertiary prevention then it has real policy implications because the cost of treating established illness will be saved. The amount of cost-saving would depend upon the effectiveness of prevention and early detection/ treatment strategies. Moreover, this would also bring about changes in life expectancy and the quality of life in individuals who would have otherwise died or suffered from distress and disability. However, the risk of cost of illness studies is that economically less significant disorders will be neglected.

Croft-Jefferys, C. \& WILKINSON, G. (1989). Estimated costs of neurotic disorders in UK general practice 1985. Psychological Medicine, 19. 549-558.

Sнан, A. K. (1995) The measurement of the economic burden of psychiatric illness in old age. Australian Journal of Ageing. 14, 3-5.

Sмrth, K. Shah, A. K., Wright, K., et al (1995). The prevalence and costs of psychiatric disorders and learning disabilities. British Joumal of Psychiatry. 168, 9-18.

AJIT SHAH, Senior Lecturer in Psychiatry of Old Age, West Middlesex Hospital. Twickenham Road, Isleworth, Middlesex TW7 6AF
Authors' reply: Shah suggests that failure to discuss cost of illness studies was an important omission from our recent articles on economic evaluation. Economic evaluation is the comparative analysis of alternative actions in terms of costs and consequences (Rovira, 1995) to inform health-care resource allocation decisions. Cost of illness studies, as Shah points out, measure the economic burden of disease. They do not examine alternative responses to reducing the burden of disease and they do not compare costs to consequences. We therefore left cost of illness studies out of our short series because they are not forms of economic evaluation as economists conventionally define it.

This is not to say they are not useful forms of analysis. Some authors have suggested they are not (Shiell et al, 1987), but this view is contested (Behrens \& Klaus-Dirk, 1988; Hodgson, 1989). Cost of illness studies can reveal unexpected distributions in the burden of disease; bring together data on the total current costs of meeting disease in ways which routine health and social service data, arranged on a service or specialty basis, can not; suggest the potential for resource savings through effective prevention or other forms of early intervention; and highlight disease problems which demand action of some kind because of the health burden they impose on both the population and the formal and informal caring services (Knapp, 1997).

However, cost of illness studies cannot, in themselves, indicate where treatment resources should be directed. It may be neither effective nor cost-effective to treat the more expensive disorders referred to by Shah. The expense of the existing response may reflect an inefficient use of resources, the circular argument referred to by Shiell et al (1987), rather than a need which can be effectively and efficiently met. Cost of illness studies in themselves are not therefore an appropriate basis for resource allocation decisions. A significant burden of disease suggests a pressing need for health-care resources, but the priority attached, in terms of resources allocated, to meeting that need should reflect the effectiveness, cost-effectiveness and cost-benefit of the alternative treatments available, information generated through economic evaluation. Cost of illness studies are complementary to but distinct from economic evaluation.

BEHRENS, C. \& KLAUS-DiRK, H. (1988) Cost of illness studies: no aid to decision making? Reply to Shiell et al. Health Policy, 10. 137-141. 